\title{
Promoter Region Hypermethylation and mRNA Expression of MGMT and $p 16$ Genes in Tissue and Blood Samples of Human Premalignant Oral Lesions and Oral Squamous Cell Carcinoma
}

\author{
Vikram Bhatia, ${ }^{1}$ Madhu Mati Goel, ${ }^{1}$ Annu Makker, ${ }^{1}$ Shikha Tewari, ${ }^{2}$ Alka Yadu, \\ Priyanka Shilpi, ${ }^{1}$ Sandeep Kumar, ${ }^{4}$ S. P. Agarwal, ${ }^{5}$ and Sudhir K. Goel ${ }^{2,6}$ \\ ${ }^{1}$ Department of Pathology, King George's Medical University, Lucknow 226003, India \\ ${ }^{2}$ Petroleum Toxicology Division, CSIR-Indian Institute of Toxicology Research (CSIR-IITR), Lucknow 226003, India \\ ${ }^{3}$ Department of Biochemistry, Saraswati Dental College, Lucknow 227105, India \\ ${ }^{4}$ All India Institute of Medical Sciences, Bhopal, Madhya Pradesh 462026, India \\ ${ }^{5}$ Department of Otorhinolaryngology, King George's Medical University, Lucknow 226003, India \\ ${ }^{6}$ Department of Biochemistry, All India Institute of Medical Sciences, Bhopal, Madhya Pradesh 462026, India
}

Correspondence should be addressed to Madhu Mati Goel; madhukgmc@gmail.com

Received 19 February 2014; Revised 23 April 2014; Accepted 13 May 2014; Published 2 June 2014

Academic Editor: Fumio Imazeki

Copyright (C) 2014 Vikram Bhatia et al. This is an open access article distributed under the Creative Commons Attribution License, which permits unrestricted use, distribution, and reproduction in any medium, provided the original work is properly cited.

\begin{abstract}
Promoter methylation and relative gene expression of $\mathrm{O}^{6}$-methyguanine-DNA-methyltransferase (MGMT) and p16 genes were examined in tissue and blood samples of patients with premalignant oral lesions (PMOLs) and oral squamous cell carcinoma (OSCC). Methylation-specific PCR and reverse transcriptase PCR were performed in 146 tissue and blood samples from controls and patients with PMOLs and OSCC. In PMOL group, significant promoter methylation of MGMT and p16 genes was observed in 59\% $(P=0.0010)$ and $57 \%(P=0.0016)$ of tissue samples, respectively, and $39 \%(P=0.0135)$ and $33 \%(P=0.0074)$ of blood samples, respectively. Promoter methylation of both genes was more frequent in patients with OSCC, that is, 76\% $(P=0.0001)$ and $82 \%(P=0.0001)$ in tissue and $57 \%(P=0.0002)$ and $70 \%(P=0.0001)$ in blood, respectively. Significant downregulation of MGMT and p16 mRNA expression was observed in both tissue and blood samples from patients with PMOLs and OSCC. Hypermethylation-induced transcriptional silencing of MGMT and p16 genes in both precancer and cancer suggests important role of these changes in progression of premalignant state to malignancy. Results support use of blood as potential surrogate to tissue samples for screening or diagnosing PMOLs and early OSCC.
\end{abstract}

\section{Introduction}

Worldwide, oral squamous cell carcinoma ranks the sixth most common cancer and accounts for $3-5 \%$ of all human malignancies $[1,2]$. It is the most frequent cancer of head and neck region which encompass tumors arising from the epithelium of the nasal, oral cavity, pharynx, and larynx [3]. In India, oral cancer ranks as number one amongst all cancers in males and number three amongst all cancers in females. Tobacco smoking and alcohol consumption are established risk factors associated with OSCC and the most common oral premalignancies [4]. It is reported that different carcinogens activate or inhibit specific pathways during cancer development and progression. The oral habits of tobacco and betel quid chewing, bidi (tobacco flakes wrapped in a tendu leaf) smoking, and alcohol consumption have been documented as risk factors for OSCC in Indian population and the most prevalent tumor sites are mouth and oropharynx [5]. All the above forms of tobacco are known to contain hydrocarbons and several potent nitrosamines which are carcinogenic and act via alterations in DNA thus playing a key role in initiation and promotion of oral cancer [6].

OSCC arises as a result of multiple molecular events that develop from the combined influences of an individual's 
genetic predisposition, immunodeficiency, and external agents such as dietary factors and viruses and like human papilloma virus (HPV) and Epstein-Barr virus (EBV) $[7,8]$. Accumulation of genetic alterations can lead to the development of premalignant lesions and subsequent invasive carcinoma. Correct diagnosis of premalignant oral lesions enables treatment before progression to an invasive neoplasm. The most common premalignant lesions in the oral cavity are leukoplakia with and without dysplasia, submucosal fibrosis (SMF), and oral lichen planus (OLP) [9]. Estimates of the global prevalence of oral potentially malignant disorders range from 1 to $5 \%$ [10]. Both genetic and epigenetic changes are known to contribute to tumorigenesis in humans. While genetic alterations refer to irreversible changes in DNA sequence leading to oncogene activation or tumor suppressor gene inactivation $[1,11]$, epigenetic changes denote reversible and heritable modifications in gene expression without any alterations in the DNA sequence. DNA methylation is the most significant epigenetic modification in eukaryotic genome which plays a key role in many existing cellular pathways including apoptosis, cell adherence, DNA repair, and cell-cycle control and during the development of cancer [12-14]. Aberrant DNA methylation includes genomewide hypomethylation as well as promoter $\mathrm{CpG}$ island hypermethylation [15]. Several studies have reported certain cancer-related genes to be frequently methylated in oral malignancies. Among these are $\mathrm{O}^{6}$-methyguanine-DNAmethyltransferase (MGMT) and p16 genes. MGMT (located on chromosome 10q26) is a detoxifying agent of DNA adducts and prevents alkylation [14]. It encodes DNA-repair protein $\mathrm{O}^{6}$-alkylguanine DNA alkyltransferase (AGT) which repairs potentially mutagenic and cytotoxic alkylation of DNA by removing adducts from the $\mathrm{O}^{6}$ position on guanine [16]. It is now well established that DNA adducts are formed by alkylating intermediates under exposure to tobacco intake [17]. Inactivation of MGMT occurs rarely owing to deletion, mutation, or rearrangement of the MGMT gene [13]. Previous studies have found that loss of MGMT protein expression is predominantly associated with hypermethylation of the promoter region in a variety of primary human cancers $[14,16$, 18-20] suggesting that inactivation of this DNA repair mechanism may be an important step in human tumorigenesis. Reports on transcriptional silencing of MGMT gene in OSCC have shown that frequency of MGMT promoter methylation ranges from 23 to $56 \%$ in tumor tissue as compared to $9 \%$ in healthy oral mucosa suggesting that inactivation of this DNA repair mechanism may be a significant event in oral carcinogenesis [20,21]. However, loss of expression of MGMT by promoter hypermethylation in premalignant oral lesions has received relatively little attention.

The p16 gene (located on chromosome 9p21) plays a key role in cell cycle regulation and codes for a protein which binds and inhibits cyclin-dependent kinases (CdK-4 and -6) and phosphorylates serine and threonine residues of retinoblastoma $(\mathrm{Rb})$ protein $[22,23]$. The p16 promoter region methylation has been reported to vary between 17 and $43 \%$ in oral cancer cell lines, 23 and $67 \%$ in primary tumors, and $0 \%$ in healthy oral mucosa [24-27]. Frequent $p 16$ hypermethylation has been observed in premalignant oral lesions by Hall et al. [28] and it was reported that these lesions tend to be transformed into OSCC.

Blood is one of the most easily available (noninvasive) clinical samples and tumor DNA is known to be present in blood stream as cell free DNA circulating in the plasma or serum of cancer patients [29-32]. Genetic and epigenetic alterations including point mutations, microsatellite instabilities (MI), losses of heterozygosity ( $\mathrm{LOH})$, and DNA hypermethylations have been reported in circulating DNA. In many cases, these changes were found to be identical to those in the primary tumor tissue of the patient, supporting the tumoral origin of altered cell free DNA [30]. Although presence of alterations in cell free DNA, as well as its overall increase, is not restricted to any particular tumor site, type, or grade, there is however a tendency for significantly larger amounts of circulating DNA in patients with late stage disease and metastasis [29]. Thus, blood may serve as an important surrogate material for cell free DNA-based molecular analysis in cancer and precancer patients. Elucidation of the pathogenesis and establishment of effective treatment are significant challenges in oral oncology; however, many aspects of oral carcinogenesis are still poorly understood. In order to gain a mechanistic insight into the complex molecular events leading to the progression of premalignant oral lesions to cancer, in the present study we looked for the promoter region methylation status of MGMT and p16 genes in the blood and tissue samples of patients with premalignant oral lesions and OSCC. In addition, relative gene expression assay was conducted to analyse transcriptional dysregulation of these two genes in tissue and blood samples of both premalignant and malignant lesions. The methylation induced gene silencing was finally correlated with the known risk factors in Indian population.

\section{Materials and Methods}

2.1. Study Samples. A total of 146 biopsy proven cases in 3 groups, namely, control $(n=16)$, premalignant oral lesions $(n=54)$, and OSCC $(n=76)$, were included in this study. Tissue biopsies and peripheral blood samples were collected from Departments of Oral and Maxillofacial Surgery and Otolaryngology of King George's Medical University, Lucknow, and Department of Oral and Maxillofacial Surgery of Saraswati Dental College, Lucknow. The study was approved by the Institutional Ethics Committee of King George's Medical University, Lucknow, India, in the meeting of March 12, 2011. Written informed consent was obtained from all participants of the study.

Histologically confirmed samples lacking any malignancy or premalignant oral lesions were included as controls in the study. The demographic and clinical history of each patient was recorded on a standard questionnaire. The samples were collected in Trizol reagent (Invitrogen, Carlsbad CA, USA) and stored immediately at $-80^{\circ} \mathrm{C}$ till further processing for DNA and RNA isolation. 


\subsection{Methylation Study}

2.2.1. DNA Extraction and Purification. Genomic DNA was isolated by phenol/chloroform extraction method followed by ethanol precipitation as described by Sambrook et al. [33]. DNA was purified using Wizard genomic DNA purification kit (Promega) and after quantification on Picodrop spectrophotometer (Picodrop, UK) at 260/280 nm wavelength it was stored at $-20^{\circ} \mathrm{C}$ till use.

2.2.2. Bisulfite Modification. Bisulfite conversion of genomic DNA (200-500 ng) was performed using commercially available kit (MethylCode Bisulfite conversion kit, Invitrogen, CA). Briefly, DNA from tissue and blood was treated with conversion reagent and incubated in thermal cycler at $64^{\circ} \mathrm{C}$ for $2.5 \mathrm{hrs}$, followed by purification and desulphonation steps. Finally, the converted DNA was eluted and stored at $-20^{\circ} \mathrm{C}$ till further use. The bisulfite-treated DNA was used as template for methylation-specific PCR (MSP).

2.2.3. Methylation Specific PCR (MSP). Methylation was done by MSP method [34] with slight modifications. Nested PCR was performed to analyze the promoter methylation status of the MGMT and p16 genes [35]. During 1st step PCR, the primers recognized the bisulfite modified template but did not discriminate between the methylated and unmethylated alleles. PCR amplification was carried out in a $20 \mu \mathrm{L}$ reaction mixture containing $10 \mu \mathrm{L}$ of Platinum Super PCR master mix consisting of Taq DNA polymerase with Platinum Taq Antibody, $22 \mathrm{mM}$ Tris- $\mathrm{HCl}$ (pH 8.4), $55 \mathrm{mM} \mathrm{KCl}, 1.65 \mathrm{mM}$ $\mathrm{MgCl}_{2}, 220 \mu \mathrm{M}$ of each dNTP (Invitrogen, CA, USA), $1 \mu \mathrm{L}$ of $10 \mu \mathrm{M}$ of forward and reverse primers, and $1 \mu \mathrm{L}(250 \mathrm{ng})$ of bisulfite-treated DNA. The reaction was heated at $95^{\circ} \mathrm{C}$ for 10 minutes and then amplified for 40 cycles $\left(95^{\circ} \mathrm{C} / 30\right.$ seconds, $64^{\circ} \mathrm{C}$ (for p16) or $52^{\circ} \mathrm{C}$ (for MGMT) $/ 30$ seconds, and $72^{\circ} \mathrm{C} / 30$ seconds), followed by a final 10 -minute extension at $72^{\circ} \mathrm{C}$. 1st step PCR product was diluted 10 -fold and $1 \mu \mathrm{L}$ was used for the 2nd step PCR, using the same reagents and conditions as in 1st step PCR. Each sample was further amplified in two reactions: one containing primers specific for methylated cytosine and the other containing primers specific for unmethylated cytosine. Each reaction was heated at $95^{\circ} \mathrm{C}$ for 10 minutes and then amplified for 40 cycles, each consisting (for the reaction containing methylated primers) of $95^{\circ} \mathrm{C} / 30$ seconds, $70^{\circ} \mathrm{C}$ (for p16) or $64^{\circ} \mathrm{C}$ (for $M G M T$ ) $/ 30$ seconds, and $72^{\circ} \mathrm{C} / 30$ seconds, and (for the reaction containing unmethylated primers) of $95^{\circ} \mathrm{C} / 30$ seconds, $64^{\circ} \mathrm{C}$ (for both $p 16$ and $M G M T$ ) $/ 30$ seconds, and $72^{\circ} \mathrm{C} / 30$ seconds [36]. The nucleotide sequences of the primers for twostage MSP were described previously by Liu et al. [36]. Methylated and unmethylated genomic DNA (Cells-to-CpG Methylated and Unmethylated genomic DNA Control Kit, Applied Biosystem, CA) were used as positive controls. PCR product was visualized with $4 \%$ agarose gel electrophoresis (AGE).

The MSP PCR products were analyzed by restriction fragment length polymorphism (RFLP) to confirm their "methylated" status as described by Liu et al. [36]. Briefly, $2 \mu \mathrm{L}$ of aliquot from nested MSP product was treated in a final
$10 \mu \mathrm{L}$ reaction with the restriction enzyme Fnu $4 \mathrm{H} 1$ for the p16 gene, and with TaqI and BstU1 for the MGMT gene using reagents and conditions provided by the manufacturer (New England Biolabs, Beverly, MA). Fnu4H1 and BstU1 restriction enzymes both are methylation sensitive, and TaqI is methylation insensitive. The digested product was separated on $2 \%$ AGE and visualized in UV light using gel documentation system. Methylated and unmethylated positive controls DNA were also digested with the same restriction enzymes.

\subsection{Gene Expression Study}

2.3.1. RNA Extraction. RNA was extracted from frozen tissue and blood samples with Trizol reagent (Invitrogen, Carlsbad, CA) [37]. RNA purification was done by DNasel (Invitrogen, Amplification grade) treatment. In brief, $1 \mu \mathrm{g}$ of total RNA sample was treated with DNase I $(1 \mathrm{U} / 10 \mu \mathrm{L})$ and incubated for $15 \mathrm{~min}$ at room temperature followed by enzyme inactivation with $25 \mathrm{mM}$ EDTA at $65^{\circ} \mathrm{C}$ for $10 \mathrm{~min}$. RNA was quantified on a Picodrop spectrophotometer (Picodrop, UK) at $260 / 280 \mathrm{~nm}$ wavelength.

2.3.2. cDNA Synthesis (Reverse Transcriptase PCR). $250 \mathrm{ng}$ of the total RNA was subjected to reverse transcription PCR using random hexamer primers with high capacity cDNA reverse transcription kit (Applied Biosystems, CA) for cDNA synthesis as per manufacturer's instruction. Briefly, the $20 \mu \mathrm{L}$ reaction was performed in 3 incubation steps: $25^{\circ} \mathrm{C}$ for $10 \mathrm{~min}$ followed by $37^{\circ} \mathrm{C}$ for $2 \mathrm{hrs}$ and finally $85^{\circ} \mathrm{C}$ for $5 \mathrm{~min}$. cDNA was stored at $-20^{\circ} \mathrm{C}$ until use for real-time PCR.

2.3.3. Quantitative Real-Time PCR ( $q P C R$ ). qPCR was performed in the presence of SYBR Green fluorescent dye using a StepOne Real-time PCR system (Applied Biosystems, CA, USA). Briefly, the reaction mixture consisted of reverse transcribed cDNA, 2X POWER SYBR Green master mix (Applied Biosystem), and $10 \mu \mathrm{M}$ of forward and reverse primers. The primer sequences for MGMT, $p 16$, and $\beta$-Actin gene were selected from published articles [38-40] and synthesized by Eurofins MWG Operon, India. Primer sequences were crosschecked by Primer Express software 3.0 (Applied Biosystems, USA) and Blast sequence analysis (National Centre for Biotechnology Information, USA). Relative gene expression was determined by the $2^{-\Delta \Delta \mathrm{Ct}}$ method using beta-actin as an endogenous control [37]. A negative control without template was run in parallel to assess the overall specificity of the reaction. All reactions were run in triplicates.

2.4. Statistical Analysis. Data was presented as frequencies and percentages for categorical variables. Methylation and unmethylation frequency and their correlation with clinicopathological variables were evaluated by chi-square $\left(\chi^{2}\right)$ test using GraphPad prism software (Version3.0, GraphPad Software, USA). The real-time PCR data was analyzed using Expression Suit software vl.0 (Life Technology, Applied Biosystem). The results were considered statistically significant at a $P$ value $\leq 0.05$. 
TABle 1: Mean age and sex of patients and their distribution according to exposure to risk factors.

\begin{tabular}{|c|c|c|c|c|c|c|}
\hline \multirow{2}{*}{ Features } & \multirow{2}{*}{ Control $(n=16)$} & \multicolumn{4}{|c|}{ PMOLs $(n=54)$} & \multirow{2}{*}{$\operatorname{OSCC}(n=76)$} \\
\hline & & $\operatorname{LKP}(n=22)$ & $\operatorname{LKPD}(n=11)$ & $\operatorname{SMF}(n=13)$ & $\operatorname{OLP}(n=8)$ & \\
\hline Age \pm SD (Yrs) & $29 \pm 8.28$ & $39 \pm 13.59$ & $34 \pm 11$ & $40 \pm 13$ & $34 \pm 8$ & $53 \pm 12.97$ \\
\hline $\operatorname{Sex}(M / F)$ & $12 / 4$ & $19 / 3$ & $10 / 1$ & $11 / 2$ & $7 / 1$ & $69 / 7$ \\
\hline Tobacco consumers & $9(56 \%)$ & $20(91 \%)$ & $10(91 \%)$ & $13(100 \%)$ & $8(100 \%)$ & $59(78 \%)$ \\
\hline Alcohol consumers & $5(31 \%)$ & $6(27 \%)$ & $3(27 \%)$ & - $^{\#}$ & $3(38 \%)$ & $19(25 \%)$ \\
\hline Pan masala users & $3(19 \%)$ & $10(45 \%)$ & $7(64 \%)$ & $3(23 \%)$ & $5(63 \%)$ & $23(30 \%)$ \\
\hline Bidi smokers & $10(62.5 \%)$ & $15(68 \%)$ & $7(64 \%)$ & $8(62 \%)$ & $5(62.5 \%)$ & $43(57 \%)$ \\
\hline
\end{tabular}

M: male, F: female; SD: standard deviation. PMOLs: premalignant oral lesions; LKP and LKPD: leukoplakia with and without dysplasia; SMF: submucosal fibrosis; OLP: oral lichen planus.

\# Out of 13 SMF patients none of the patients was found to have the habit of alcohol drinking.

\section{Results}

3.1. Demographic and Clinical Characteristics. Demographic and clinical characteristics (age, gender, and habits like tobacco, alcohol, bidi, and pan masala consumption) of the patients recruited for the study are summarized in Table 1. Although selection of patients for the study was unbiased, the number of males in the study was more than females. The tobacco consuming habit was more in patients with premalignant oral lesions (90-100\%) and OSCC (78\%) as compared to controls (56\%). Similarly, the number of PMOL and OSCC patients with the habits of alcohol drinking, pan masala chewing and bidi smoking were higher as compared to controls.

3.2. Analysis of Gene Promoter Methylation. MGMT and p16 gene showed similar methylation pattern in tissue and blood DNA samples from patients with premalignant oral lesions (leukoplakia with and without dysplasia, SMF, and OLP) and OSCC (Table 2). Significant promoter region methylation of MGMT gene was observed in 59\% and $76 \%$ of tissue samples and $39 \%$ and $57 \%$ of blood samples in the premalignant oral lesion and OSCC groups, respectively, while 13\% methylation was observed in tissue samples and 6\% in blood samples of the control group. Significant promoter region methylation of $p 16$ gene was observed in $57 \%$ and $82 \%$ of tissue samples and $33 \%$ and $70 \%$ of blood samples in the premalignant oral lesion and OSCC groups, respectively, while $13 \%$ methylation was observed in tissue samples and there was no methylation in blood samples of the controls. We also observed different frequencies of unmethylation in tissue and blood DNA of control, premalignant oral lesions, and OSCC groups; however, the data was not statistically significant. As compared to controls, MGMT promoter methylation was significantly higher in tissue and blood samples of premalignant oral lesions and OSCC. Among premalignant oral lesions, MGMT methylation frequency in tissue samples was the highest for leukoplakia with dysplasia $(73 \%, P=0.0002)$ followed by leukoplakia without dysplasia (73\%, $P=0.0015)$, SMF (46\%, $P=0.0437)$, and OLP (25\%, $P=0.4386 \mathrm{NS})$. However, in blood samples methylation was significantly the highest in leukoplakia without dysplasia $(55 \%, P=0.0049)$ followed by leukoplakia with dysplasia $(41 \%, P=0.0166)$, SMF $(31 \%$, $P=0.0821, \mathrm{NS})$, and OLP (25\%, $P=0.1904 \mathrm{NS})$. The $M G M T$ gene methylation in the OSCC group was significantly higher than that observed for all subgroups of premalignant oral lesions ( $P=0.0379$ for tissue and 0.0468 for blood samples). PCR products of $M G M T$ gene methylation were visualized on $4 \%$ AGE.

The p16 gene methylation frequency in tissue samples of premalignant oral lesions was the highest in leukoplakia with dysplasia $(68 \%, P=0.0007)$ followed by $\operatorname{SMF}(62 \%$, $P=0.0057)$, OLP $(50 \%, P=0.0455)$, and leukoplakia without dysplasia ( $36 \%, P=0.1428 \mathrm{NS})$. In blood samples, this was the highest in SMF $(46 \%, P=0.0023)$ followed by leukoplakia with dysplasia $(45 \%, P=0.0017)$ followed by leukoplakia without dysplasia $(18 \%, P=0.0763 \mathrm{NS})$ and OLP (0\%). The methylation for p16 was significant in tissue and blood samples from all subgroups of premalignant oral lesion and OSCC patients as compared to controls. PCR products of p16 gene methylation were visualized on $4 \%$ AGE. MSP result was confirmed by RFLP. TaqI, BstU1, and FNU4H1 restriction enzymes cut only templates containing methylated cytosines (methylated template). In case of unmethylated templates where the unmethylated cytosines are transformed by bisulfite treatment into uracils (converted to thymidine after PCR), the product is not digested by the enzyme. All methylation positive samples showed presence of digestion products on RFLP (see Supplementary Figures 1(a) and 1(b) in Supplementary Material available online at http://dx.doi.org/10.1155/2014/248419).

3.3. Relative Gene Expression of MGMT and p16 Gene. The mRNA expression of MGMT and 16 genes was significantly downregulated in both tissue and blood samples of premalignant oral lesions (leukoplakia with and without dysplasia, and SMF) and OSCC ( $P \leq 0.05)$. Relative MGMT and p16 mRNA expression was nonsignificant both in tissue and blood samples of cases with OLP (Figure 1).

3.4. Correlation with Risk Factors. Known risk factors for OSCC, namely tobacco, bidi, alcohol, and pan masala consumption, were found to contribute to promoter region methylation of both MGMT and p16 genes in controls, premalignant oral lesions, and OSCC groups. While tobacco chewing $(P=0.041$ and $P=0.015$ for tissue and blood samples, resp.) and bidi smoking $(P=0.038$ and $P=0.048$ for tissue and blood samples, resp.) showed 
TABLE 2: Methylation profile of MGMT and p16 genes in tissue and blood samples of study groups.

\begin{tabular}{|c|c|c|c|c|c|c|c|}
\hline \multirow{2}{*}{ Gene methylation } & \multirow{2}{*}{ Groups } & \multicolumn{3}{|c|}{ Tissue } & \multicolumn{3}{|c|}{ Blood } \\
\hline & & $M^{*}$ & $\mathrm{U}$ & $P$ value $^{\mathrm{a}}$ & $M^{*}$ & $\mathrm{U}$ & $P$ value $^{\mathrm{a}}$ \\
\hline \multirow{8}{*}{$M G M T$} & Control $(n=16)$ & $2(13 \%)$ & $14(87 \%)$ & Ref & $1(6 \%)$ & $15(94 \%)$ & Ref \\
\hline & PMOLs $(n=54)$ & $32(59 \%)$ & $22(41 \%)$ & 0.001 & $21(39 \%)$ & $33(61 \%)$ & 0.0135 \\
\hline & PMOL subtypes & & & & & & \\
\hline & $\operatorname{LKP}(n=22)$ & $16(73 \%)$ & $6(27 \%)$ & 0.0002 & $9(41 \%)$ & $13(59 \%)$ & 0.0166 \\
\hline & $\operatorname{LKPD}(n=11)$ & $8(73 \%)$ & $3(27 \%)$ & 0.0015 & $6(55 \%)$ & $5(45 \%)$ & 0.0049 \\
\hline & $\operatorname{SMF}(n=13)$ & $6(46 \%)$ & $7(54 \%)$ & 0.0437 & $4(31 \%)$ & $9(69 \%)$ & 0.0821 \\
\hline & $\operatorname{OLP}(n=8)$ & $2(25 \%)$ & $6(75 \%)$ & 0.4386 & $2(25 \%)$ & $6(75 \%)$ & 0.1904 \\
\hline & $\operatorname{OsCC}(n=76)$ & $58(76 \%)$ & $18(24 \%)$ & 0.0001 & $43(57 \%)$ & $33(43 \%)$ & 0.0002 \\
\hline$P$ value $^{\mathrm{b}}$ & PMOLs versus OSCC & - & - & 0.0379 & - & - & 0.0468 \\
\hline \multirow{8}{*}{ p16 } & Control $(n=16)$ & $2(13 \%)$ & $14(87 \%)$ & Ref & $0(0 \%)$ & $16(100 \%)$ & Ref \\
\hline & PMOLs $(n=54)$ & $31(57 \%)$ & $23(43 \%)$ & 0.0016 & $18(33 \%)$ & $36(67 \%)$ & 0.0074 \\
\hline & PMOL subtypes & & & & & & \\
\hline & $\operatorname{LKP}(n=22)$ & $15(68 \%)$ & $7(32 \%)$ & 0.0007 & $10(45 \%)$ & $12(55 \%)$ & 0.0017 \\
\hline & $\operatorname{LKPD}(n=11)$ & $4(36 \%)$ & $7(64 \%)$ & 0.1428 & $2(18 \%)$ & $9(82 \%)$ & 0.0763 \\
\hline & $\operatorname{SMF}(n=13)$ & $8(62 \%)$ & $5(38 \%)$ & 0.0057 & $6(46 \%)$ & $7(54 \%)$ & 0.0023 \\
\hline & $\mathrm{OLP}(n=8)$ & $4(50 \%)$ & $4(50 \%)$ & 0.0455 & $0(0 \%)$ & $8(100 \%)$ & NA \\
\hline & $\operatorname{OsCC}(n=76)$ & $62(82 \%)$ & $14(18 \%)$ & 0.0001 & $53(70 \%)$ & $23(30 \%)$ & 0.0001 \\
\hline$P$ value $^{\mathrm{b}}$ & PMOLs versus OSCC & - & - & 0.0026 & - & - & 0.0001 \\
\hline
\end{tabular}

M: methylated, U: umethylated, and Ref: reference; ${ }^{\mathrm{a}} \mathrm{Chi}$-square test considering control as reference category; ${ }^{\mathrm{b}} \mathrm{Chi}$-square test considering PMOLs as reference category.

* Methylated group includes samples showing complete methylation (only methylated amplicon) as well as samples showing partial methylation (both methylated and unmethylated amplicons).

Relative MGMT mRNA expression

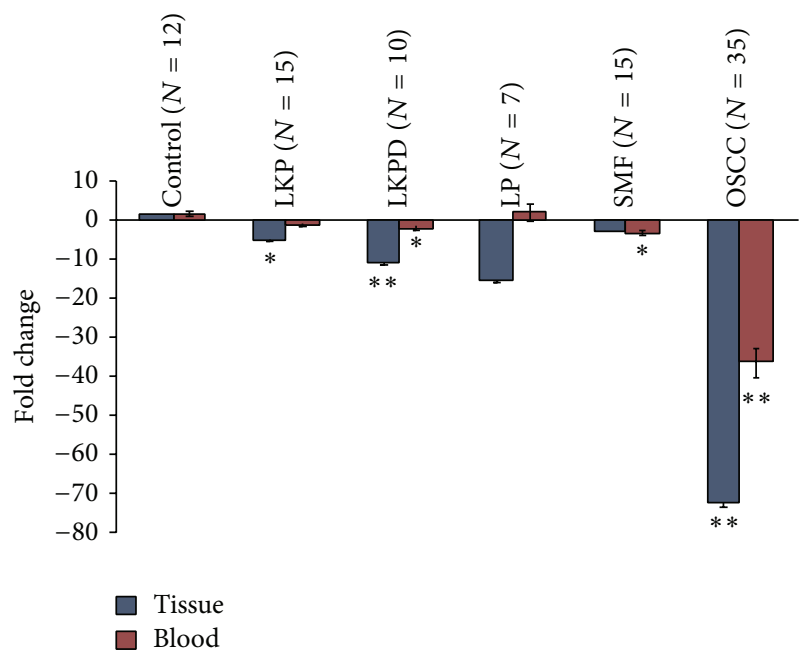

(a)
Relative $p 16$ mRNA expression level

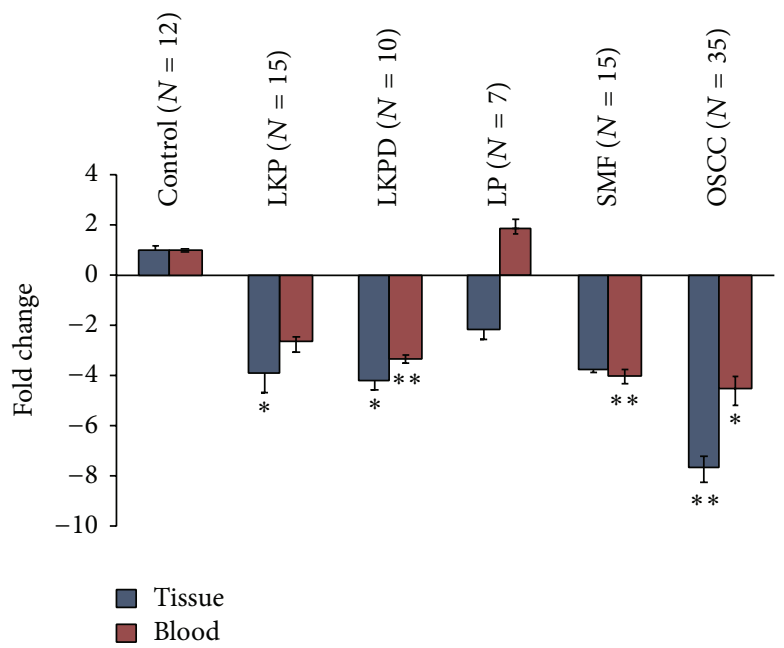

(b)

FIGURE 1: Relative mRNA expression level of $M G M T$ and p16 genes in tissue and blood samples of different groups. Statistically significant values were represented by ${ }^{*} P<0.05,{ }^{* *} P<0.01$, and ${ }^{* * *} P<0.001$.

significant association with methylation of MGMT gene in all groups, $p 16$ gene methylation was significantly associated with tobacco chewing $(P=0.049)$, pan masala $(P=0.007)$, and bidi smoking $(P=0.015)$ only in tissue samples of all study groups (Table 3 ).

\section{Discussion}

In the present study, we examined the methylation pattern and gene expression of MGMT and p16 gene in histologically proven biopsies and corresponding blood samples 
TABLE 3: Correlation of promoter methylation with risk factors in different groups.

\begin{tabular}{|c|c|c|c|c|c|c|}
\hline Genes & Risk factors & Methylated & Control $(n=16)$ & PMOLs $(n=54)$ & OSCC $(n=76)$ & $P$ value $^{\mathrm{a}}$ \\
\hline \multirow{12}{*}{$M G M T$} & \multirow{3}{*}{ Tobacco chewers $(N)$} & $N$ & 9 & 51 & 59 & \\
\hline & & Tissue & $2(22 \%)$ & $24(47 \%)$ & $52(88 \%)$ & 0.041 \\
\hline & & Blood & $1(11 \%)$ & $14(27 \%)$ & $39(66 \%)$ & 0.015 \\
\hline & \multirow{3}{*}{ Alcohol consumers $(N)$} & $N$ & 5 & 12 & 19 & \\
\hline & & Tissue & $0(0 \%)$ & $8(67 \%)$ & $10(53 \%)$ & 0.1588 \\
\hline & & Blood & $0(0 \%)$ & $7(58 \%)$ & $7(37 \%)$ & 0.259 \\
\hline & \multirow{3}{*}{ Pan masala $(N)$} & $N$ & 3 & 25 & 23 & \\
\hline & & Tissue & $1(33 \%)$ & $15(60 \%)$ & $14(61 \%)$ & 0.877 \\
\hline & & Blood & $0(0 \%)$ & $8(32 \%)$ & $14(61 \%)$ & 0.236 \\
\hline & \multirow{3}{*}{ Bidi smokers $(N)$} & $N$ & 10 & 35 & 43 & \\
\hline & & Tissue & $2(20 \%)$ & $20(57 \%)$ & $38(88 \%)$ & 0.038 \\
\hline & & Blood & $1(10 \%)$ & $15(43 \%)$ & $33(77 \%)$ & 0.048 \\
\hline \multirow{12}{*}{ p16 } & \multirow{3}{*}{ Tobacco chewers $(N)$} & $N$ & 9 & 51 & 59 & \\
\hline & & Tissue & $2(22 \%)$ & $25(49 \%)$ & $51(86 \%)$ & 0.049 \\
\hline & & Blood & $0(0 \%)$ & $18(35 \%)$ & $50(85 \%)$ & 0.088 \\
\hline & \multirow{3}{*}{ Alcohol consumers $(N)$} & $N$ & 5 & 12 & 19 & \\
\hline & & Tissue & $0(0 \%)$ & $8(67 \%)$ & $11(58 \%)$ & 0.124 \\
\hline & & Blood & $0(0 \%)$ & $6(50 \%)$ & $8(42 \%)$ & 0.278 \\
\hline & \multirow{3}{*}{ Pan masala $(N)$} & $N$ & 3 & 25 & 23 & \\
\hline & & Tissue & $2(67 \%)$ & $19(76 \%)$ & $18(78 \%)$ & 0.015 \\
\hline & & Blood & $0(0 \%)$ & $11(44 \%)$ & $17(74 \%)$ & 0.107 \\
\hline & \multirow{3}{*}{ Bidi smokers $(N)$} & $N$ & 10 & 35 & 43 & \\
\hline & & Tissue & $2(20 \%)$ & $29(83 \%)$ & $40(93 \%)$ & 0.007 \\
\hline & & Blood & $0(0 \%)$ & $15(43 \%)$ & $38(88 \%)$ & 0.071 \\
\hline
\end{tabular}

${ }^{a}$ Chi-square test; $n=$ total number of samples in the group; $N=$ number of individuals exposed to risk factors in different groups. Significant $P$ value represented with bold.

from patients with oral premalignant and malignant lesions and correlated them with known risk factors. We observed significant association of MGMT and p16 gene methylation with oral precancer and cancer.

The methylation frequency was analyzed by MSP, a simple, sensitive, and specific method for determining the promoter hypermethylation status of $\mathrm{CpG}$ islands [41]. We observed 76\% MGMT methylation frequency in OSCC tissue samples. In DNA from corresponding blood samples of these patients the frequency was $57 \%$. Our results are consistent with those of Kordi-Tamandani et al. who observed $73.7 \%$ MGMT methylation in tissue samples which was significantly different as compared to controls [42]. In another study, hypermethylation of MGMT gene in OSCC was reported to occur in $25-52 \%$ of tissue samples [43-45]. Promoter hypermethylation has been reported in premalignant lesions with and without epithelial dysplasia [46, 47]. Liu et al. observed 30.2\% MGMT methylation in oral leukoplakia [48]. Interestingly, in the present study patients of leukoplakia with and without dysplasia showed promoter methylation in tissue samples of $73 \%$ of both cases, respectively. Blood samples of these patients showed $41 \%$ and $55 \%$ methylation, respectively. We also observed an increased promoter methylation frequency of MGMT gene in tissue (46\%) and blood samples (31\%) from patients with SMF. To the best of our knowledge, there is so far no report available on MGMT promoter methylation in blood samples of patients with premalignant oral lesions and OSCC in Indian population. We found significant MGMT methylation in blood samples of leukoplakia with and without dysplasia and OSCC groups as compared to controls.

Alterations in p16 gene are known to affect cell cycle regulation, specifically when suppressing the G1 phase [22]. In the present study, $p 16$ promoter methylation was observed in tissue samples of $57 \%$ cases of premalignant oral lesions and $82 \%$ cases OSCC. Shaw et al. observed statistically significant increase in $p 16$ promoter methylation in patients with oral tumors over normal tissues [45]. In OSCC samples, p16 methylation has been reported at a frequency of $27-76 \%$ $[20,27]$. There are available reports which have shown the effect of $p 16$ methylation in precancerous oral lesions with and without epithelial dysplasia $[46,49]$ and its association with advanced OSCC [43, 50-52]. von Zeidler et al. evaluated methylation status of $p 16$ gene in premalignant oral lesions and found $9.7 \%$ of cases with promoter hypermethylation [53]. Liu et al. have reported p16 promoter methylation in $25.6 \%$ cases of leukoplakia [48]. In the present study, we found a significant $68 \%$ methylation in tissue samples and 
$45 \%$ in blood samples of leukoplakia with dysplasia. Further, the methylation frequency of $p 16$ in tissue $(62 \% ; P=0.0057)$ and blood (46\%; $P=0.0023)$ samples of patients with SMF was statistically significant. Although no studies on p16 hypermethylation are available in SMF patients, Xu et al. have reported significant hypermethylation of ECAD and COX-2 genes in blood samples from patients with SMF [54]. A recent prospective study also reported that p16 hypermethylation is significantly increased in precancerous epithelial dysplasia and associated with high rate of OSCC development [55]. These findings confirm that methylation in tumor suppressor genes is an early event that might confer cell growth advantages contributing to the tumorigenic process.

In the present study, both methylated and unmethylated DNA of MGMT and p16 genes were observed in tissue and blood samples of all three study groups. The methylated group included samples showing complete methylation (only methylated amplicon) as well as samples showing partial methylation (both methylated and unmethylated amplicons). The presence of significant level of methylation and unmethylation in DNA from same patient may be a result of cellular heterogeneity of the sample or monoallelic activation [5658]. Partial methylation observed in our study may be related to a germline first "hit" of an "expanded two hit model," of epigenetic inactivation suggested by Indovina et al. [59]. Based on this model, the epigenetic first "hit" would inactivate one allele of the both genes in all cells of the body. The partially methylated cells then could acquire a somatic second "hit" (a mutation or a second epigenetic alteration) to progress to cancer [60]. According to this hypothesis, although a methylation level of $50 \%$ was expected in peripheral blood samples of retinoblastoma patients, deviations from this value were observed in most of the reported cases [59]. Pertinently, in the present study, we observed MGMT promoter methylation in $39 \%$ and $57 \%$ blood samples of patients with premalignant oral lesions and OSCC, respectively. Significant p16 promoter methylation was observed in 33\% and 70\% blood samples of patients with premalignant oral lesions and OSCC, respectively.

Tumors that have metastasized may not shed many cells into the peripheral blood but might release tumor DNA into the circulation. Based on this finding, detection of genetic alterations and methylation abnormalities in the blood sample of cancer patients may thus have a profound impact on noninvasive diagnosis of cancers among highrisk populations. We screened blood samples of the biopsyproven cases and controls and observed that the methylation frequency of both the genes followed the same pattern as in tissue samples of patients with premalignant oral lesions and OSCC. Methylation frequency in premalignant oral lesions and OSCC was found to be significantly higher than controls suggesting use of peripheral blood as noninvasive source for early detection of oral cancer and as a surrogate marker to detect epigenetic changes. Promoter hypermethylation of $M G M T$ and $p 16$ gene in peripheral blood has been reported in primary lung cancer and nonsmall cell lung cancer patients $[15,61]$.
The functional consequence of promoter hypermethylation is transcriptional silencing of the associated genes [62]. Promoter region hypermethylation-induced MGMT gene silencing has been reported in glioblastoma multiforme, head, and neck squamous cell carcinomas in general, and also specifically in oral cavity cancer $[17,42,63,64]$. Significant downregulation of $p 16$ gene expression due to promoter hypermethylation has been reported in colorectal cancer and oral cancer $[65,66]$. In order to confirm the effect of promoter methylation on gene expression in our cases, we analyzed methylation status and mRNA levels of both MGMT and p16 genes in tissue and blood samples from various study groups. Significant downregulation of MGMT and $p 16$ gene expression was observed in both tissue and blood samples from premalignant oral lesions and OSCC patients. It is known that downregulation of MGMT gene results in decreased formation of AGT protein which repairs potentially mutagenic and cytotoxic alkylation of DNA by removing adducts from the $\mathrm{O}^{6}$ position on guanine [16]. The silencing of $p 16$ gene expression leads to decreased expression of p16 protein which plays an important role as a direct inhibitor of cyclin-dependent kinases (CDK4 and CDK6) to exert its oncosuppressor activity. Decrease or loss of p16 protein expression in the nuclei of tumor cells has also been reported in many kinds of human carcinomas [67].

In India, the main risk factors for premalignant oral lesions and OSCC are tobacco, bidi, pan masala (betel quid), alcohol consumption, and unhygienic conditions with poor nourishment $[68,69]$. High promoter methylation frequency of MGMT and p16 genes was observed in patients with premalignant oral lesions and OSCC who were tobacco chewers and bidi smokers indicating contribution of these risk factors to gene silencing by promoter hypermethylation. Our findings are in agreement with previous studies that have shown an association between tobacco consumption in chewed or smoked form and hypermethylation of both the genes in HNSCC [51, 53, 70].

The strength of our study is the well-characterized population of premalignant oral lesions and OSCC, which has detailed baseline epidemiological data on risk factors. In addition, a comparison between tissue and peripheral blood methylation from the same patients was possible because of the availability of both biological samples. Possible limitations of this study are that although this includes different subtypes of premalignant oral lesions and comparison between tissue and blood, the sample size is relatively small and longitudinal data could not be provided due to lack of follow-up data of patients with premalignant oral lesions.

To summarize, hypermethylation-induced transcriptional silencing of MGMT and p16 genes in both oral precancer and cancer distinctly separate from normal oral mucosa suggests an important role of these changes in progression of premalignant state to malignancy. Detection and quantitation of promoter region methylation may provide lesion-specific epigenetic profile and contribute significantly to screening, surveillance, and management of premalignant oral lesions and OSCC. Aberrant methylation of $M G M T$ and $p 16$ promoter could thus be a useful adjunct to 
histopathologic evaluation for prediction of risk of malignant transformation of a precancerous state. The altered DNA methylation site of the cancer epigenome is not limited to promoter hypermethylation of select genes but also includes global hypomethylation as a prelude to tumor suppressor gene inactivation, oncogene activation, and genome instability. However, an obvious limitation of the present study is that it is a cross-sectional study.

Long-term follow-up studies including measurement of DNA methylation status in promoter and nonpromoter regions (global) are required to determine the functional relevance of these alterations. Further, similar pattern of methylation for both MGMT and p16 genes in tissue and blood samples of premalignant oral lesions and OSCC suggests use of blood as a potential substitute to tissue samples for screening or diagnosing precancer and early malignancy.

\section{Conflict of Interests}

The authors declare that there is no conflict of interests regarding the publication of this paper.

\section{Acknowledgments}

Vikram Bhatia is grateful to Indian Council of Medical Research (Grant no. 3/2/2/34/2010/NCD-III) (http://www .icmr.nic.in/) for providing Senior Research Fellowship. The authors thank Dr. Vibha Pandey and Dr. Rajeev Choudary for their invaluable support during the course of this study. They are also grateful to all the study participants for their cooperation.

\section{References}

[1] M. Lingen, A. Pinto, R. Mendes et al., "Genetics/epigenetics of oral premalignancy: current status and future research," Oral Diseases, vol. 17, no. 1, pp. 7-22, 2011.

[2] S. D. da Silva, A. Ferlito, R. P. Takes et al., "Advances and applications of oral cancer basic research," Oral Oncology, vol. 47, no. 9, pp. 783-791, 2011.

[3] M. Mascolo, M. Siano, G. Ilardi et al., "Epigenetic disregulation in oral cancer," International Journal of Molecular Sciences, vol. 13, no. 2, pp. 2331-2353, 2012.

[4] D. Anantharaman, T. A. Samant, S. Sen, and M. B. Mahimkar, "Polymorphisms in tobacco metabolism and DNA repair genes modulate oral precancer and cancer risk," Oral Oncology, vol. 47, no. 9, pp. 866-872, 2011.

[5] U. Nair, H. Bartsch, and J. Nair, "Alert for an epidemic of oral cancer due to use of the betel quid substitutes gutkha and pan masala: a review of agents and causative mechanisms," Mutagenesis, vol. 19, no. 4, pp. 251-262, 2004.

[6] K. Datta, R. K. Saha, and R. N. Chakrabarti, "A simple risk estimates study for oral cavity cancer: practical approach in Indian context," Journal of the Indian Medical Association, vol. 95, no. 3, pp. 70-71, 1997.

[7] B. R. Das and J. K. Nagpal, "Understanding the biology of oral cancer," Medical Science Monitor, vol. 8, no. 11, pp. RA258RA267, 2002.

[8] E.-J. Mao and C. J. Smith, "Detection of Epstein-Barr virus (EBV) DNA by the polymerase chain reaction (PCR) in oral smears from healthy individuals and patients with squamous cell carcinoma," Journal of Oral Pathology and Medicine, vol. 22, no. 1, pp. 12-17, 1993.

[9] C. Scully, J. Sudbø, and P. M. Speight, "Progress in determining the malignant potential of oral lesions," Journal of Oral Pathology and Medicine, vol. 32, no. 5, pp. 251-256, 2003.

[10] N. W. Johnson, P. Jayasekara, A. A. Amarasinghe, and K. Hemantha, "Squamous cell carcinoma and precursor lesions of the oral cavity: epidemiology and aetiology," Periodontology 2000, vol. 57, no. 1, pp. 19-37, 2011.

[11] P. Saintigny, L. Zhang, Y.-H. Fan et al., "Gene expression profiling predicts the development of oral cancer," Cancer Prevention Research, vol. 4, no. 2, pp. 218-229, 2011.

[12] C. de Smet and A. Loriot, "DNA hypomethylation in cancer: epigenetic scars of a neoplastic journey," Epigenetics, vol. 5, no. 3, pp. 206-213, 2010.

[13] Y. Zhang, R. Wang, H. Song et al., "Methylation of multiple genes as a candidate biomarker in non-small cell lung cancer," Cancer Letters, vol. 303, no. 1, pp. 21-28, 2011.

[14] M. Esteller, "Molecular origins of cancer: epigenetics in cancer," The New England Journal of Medicine, vol. 358, no. 11, pp. 11481159, 2008.

[15] A. L. Russo, A. Thiagalingam, H. Pan et al., "Differential DNA hypermethylation of critical genes mediates the stagespecific tobacco smoke-induced neoplastic progression of lung cancer," Clinical Cancer Research, vol. 11, no. 7, pp. 24662470, 2005.

[16] A. Sabharwal and M. R. Middleton, "Exploiting the role of $\mathrm{O}^{6}$-methylguanine-DNA-methyltransferase $(M G M T)$ in cancer therapy," Current Opinion in Pharmacology, vol. 6, no. 4, pp. 355-363, 2006.

[17] C. Zuo, L. Ai, P. Ratliff et al., " $\mathrm{O}^{6}$-methylguanine-DNA methyltransferase gene: epigenetic silencing and prognostic value in head and neck squamous cell carcinoma," Cancer Epidemiology Biomarkers and Prevention, vol. 13, no. 6, pp. 967-975, 2004.

[18] C. Plass, "Cancer epigenomics," Human Molecular Genetics, vol. 11, no. 20, pp. 2479-2488, 2002.

[19] P. M. Das and R. Singal, "DNA methylation and cancer," Journal of Clinical Oncology, vol. 22, no. 22, pp. 4632-4642, 2004.

[20] R. Díez-Pérez, J. Campo-Trapero, J. Cano-Sánchez et al., "Methylation in oral cancer and pre-cancerous lesions (review)," Oncology Reports, vol. 25, no. 5, pp. 1203-1209, 2011.

[21] J. A. Gasche and A. Goel, "Epigenetic mechanisms in oral carcinogenesis," Future Oncology, vol. 8, no. 11, pp. 1407-1425, 2012.

[22] C. J. Sherr, "G1 phase progression: cycling on cue," Cell, vol. 79, no. 4, pp. 551-555, 1994.

[23] R. A. Weinberg, "The retinoblastoma protein and cell cycle control," Cell, vol. 81, no. 3, pp. 323-330, 1995.

[24] G. Šupić, R. Kozomara, M. Branković-Magić, N. Jović, and Z. Magić, "Gene hypermethylation in tumor tissue of advanced oral squamous cell carcinoma patients," Oral Oncology, vol. 45, no. 12, pp. 1051-1057, 2009.

[25] A. K. Jha, M. Nikbakht, V. Jain, N. Capalash, and J. Kaur, "P16 ${ }^{I N K 4 a}$ and $\mathrm{p} 15^{I N K 4 b}$ gene promoter methylation in cervical cancer patients," Oncology Letters, vol. 3, no. 6, pp. 1331-1335, 2012.

[26] C. Chen, N. Yin, B. Yin, and Q. Lu, "DNA methylation in thoracic neoplasms," Cancer Letters, vol. 301, no. 1, pp. 7-16, 2011.

[27] K. Kato, A. Hara, T. Kuno et al., "Aberrant promoter hypermethylation of p16 and MGMT genes in oral squamous cell 
carcinomas and the surrounding normal mucosa," Journal of Cancer Research and Clinical Oncology, vol. 132, no. 11, pp. 735743, 2006.

[28] G. L. Hall, R. J. Shaw, E. A. Field et al., "p16 promoter methylation is a potential predictor of malignant transformation in oral epithelial dysplasia," Cancer Epidemiology Biomarkers and Prevention, vol. 17, no. 8, pp. 2174-2179, 2008.

[29] E. Gormally, E. Caboux, P. Vineis, and P. Hainaut, "Circulating free DNA in plasma or serum as biomarker of carcinogenesis: practical aspects and biological significance," Mutation Research, vol. 635, no. 2-3, pp. 105-117, 2007.

[30] L. Li, J.-Y. Choi, K.-M. Lee et al., "DNA Methylation in peripheral blood: a potential biomarker for cancer molecular epidemiology," Journal of Epidemiology, vol. 22, no. 5, pp. 384394, 2012.

[31] T.-S. Wong, M. W.-L. Man, A. K.-Y. Lam, W. I. Wei, Y.-L. Kwong, and A. P.-W. Yuen, "The study of p16 and p15 gene methylation in head and neck squamous cell carcinoma and their quantitative evaluation in plasma by real-time PCR," European Journal of Cancer, vol. 39, no. 13, pp. 1881-1887, 2003.

[32] M. Sanchez-Cespedes, M. Esteller, L. Wu et al., "Gene promoter hypermethylation in tumors and serum of head and neck cancer patients," Cancer Research, vol. 60, no. 4, pp. 892-895, 2000.

[33] J. Sambrook, E. F. Fritsch, and T. Maniatis, Molecular Cloning: A laboratory manual, Cold spring Harbor Laboratory Press, Cold Spring Harbor, NY, USA, 2nd edition, 1989.

[34] J. G. Herman, J. R. Graff, S. Myöhänen, B. D. Nelkin, and S. B. Baylin, "Methylation-specific PCR: a novel PCR assay for methylation status of CpG islands," Proceedings of the National Academy of Sciences of the United States of America, vol. 93, no. 18, pp. 9821-9826, 1996.

[35] W. A. Palmisano, K. K. Divine, G. Saccomanno et al., "Predicting lung cancer by detecting aberrant promoter methylation in sputum," Cancer Research, vol. 60, no. 21, pp. 5954-5958, 2000.

[36] Y. Liu, Q. Lan, J. M. Siegfried, J. D. Luketich, and P. Keohavong, "Aberrant promoter methylation of p16 and MGMT genes in lung tumors from smoking and never-smoking lung cancer patients," Neoplasia, vol. 8, no. 1, pp. 46-51, 2006.

[37] T. D. Schmittgen and K. J. Livak, "Analyzing real-time PCR data by the comparative CT method," Nature Protocols, vol. 3, no. 6, pp. 1101-1108, 2008.

[38] Y. Kondo, L. Shen, and J.-P. J. Issa, "Critical role of histone methylation in tumor suppressor gene silencing in colorectal cancer," Molecular and Cellular Biology, vol. 23, no. 1, pp. 206215, 2003.

[39] J.-Y. Fang, Z.-H. Cheng, Y.-X. Chen et al., "Expression of Dnmt1, demethylase, $\mathrm{MeCP} 2$ and methylation of tumor-related genes in human gastric cancer," World Journal of Gastroenterology, vol. 10, no. 23, pp. 3394-3398, 2004.

[40] H. A. Marjani, F. Biramijamal, N. Rakhshani, A. HosseinNezhad, and R. Malekzadeh, "Investigation of NQO1 genetic polymorphism, NQO1 gene expression and PAH-DNA adducts in ESCC. A case-control study from Iran," Genetics and Molecular Research, vol. 9, no. 1, pp. 239-249, 2010.

[41] J. D. F. Licchesi and J. G. Herman, "Methylation-specific PCR," Methods in Molecular Biology, vol. 507, pp. 305-323, 2009.

[42] D. M. Kordi-Tamandani, A.-K. Moazeni-Roodi, M.-A. RigiLadiz, M. Hashemi, E. Birjandian, and A. Torkamanzehi, "Promoter hypermethylation and expression profile of MGMT and CDH1 genes in oral cavity cancer," Archives of Oral Biology, vol. 55, no. 10, pp. 809-814, 2010.
[43] P. K. Ha and J. A. Califano, "Promoter methylation and inactivation of tumour-suppressor genes in oral squamous-cell carcinoma," The Lancet Oncology, vol. 7, no. 1, pp. 77-82, 2006.

[44] M. Viswanathan, N. Tsuchida, and G. Shanmugam, "Promoter hypermethylation profile of tumor-associated genes $p 16, p 15$, $h M L H 1, M G M T$ and E-cadherin in oral squamous cell carcinoma," International Journal of Cancer, vol. 105, no. 1, pp. 41-46, 2003.

[45] R. J. Shaw, G. L. Hall, D. Lowe et al., "The role of pyrosequencing in head and neck cancer epigenetics: correlation of quantitative methylation data with gene expression," Archives of Otolaryngology - Head and Neck Surgery, vol. 134, no. 3, pp. 251256, 2008.

[46] R. Sailasree, A. Abhilash, K. M. Sathyan, K. R. Nalinakumari, S. Thomas, and S. Kannan, "Differential roles of $\mathrm{p} 16^{I N K 4 A}$ and p14 ${ }^{A R F}$ genes in prognosis of oral carcinoma," Cancer Epidemiology Biomarkers and Prevention, vol. 17, no. 2, pp. 414420, 2008.

[47] M. López, J. M. Aguirre, N. Cuevas et al., "Gene promoter hypermethylation in oral rinses of leukoplakia patients-a diagnostic and/or prognostic tool?" European Journal of Cancer, vol. 39, no. 16, pp. 2306-2309, 2003.

[48] M. Liu, L. Feng, X. Tang, and X. Guo, "Gene promoter hypermethylation in leukoplakia of the oral mucosa," Pathology and Laboratory Medicine International, vol. 2, pp. 71-77, 2010.

[49] J. Cao, J. Zhou, Y. Gao et al., "Methylation of p16 CpG island associated with malignant progression of oral epithelial dysplasia: a prospective cohort study," Clinical Cancer Research, vol. 15, no. 16, pp. 5178-5183, 2009.

[50] E. Ishida, M. Nakamura, M. Ikuta et al., "Promotor hypermethylation of p14ARF is a key alteration for progression of oral squamous cell carcinoma," Oral Oncology, vol. 41, no. 6, pp. 614622, 2005.

[51] V. A. Papadimitrakopoulou, J. Izzo, L. Mao et al., "Cyclin D1 and p16 alterations in advanced premalignant lesions of the upper aerodigestive tract: role in response to chemoprevention and cancer development," Clinical Cancer Research, vol. 7, no. 10, pp. 3127-3134, 2001.

[52] V. Kulkarni and D. Saranath, "Concurrent hypermethylation of multiple regulatory genes in chewing tobacco associated oral squamous cell carcinomas and adjacent normal tissues," Oral Oncology, vol. 40, no. 2, pp. 145-153, 2004.

[53] S. V. von Zeidler, E. C. Miracca, M. A. Nagai, and E. G. Birman, "Hypermethylation of the p16 gene in normal oral mucosa of smokers," International Journal of Molecular Medicine, vol. 14, no. 5, pp. 807-811, 2004.

[54] C. Xu, J. Zhao, W. T. Y. Loo et al., "Correlation of epigenetic change and identification of risk factors for oral submucous fibrosis," International Journal of Biological Markers, vol. 27, no. 4, pp. e314-e321, 2012.

[55] R. Shaw, J. M. Risk, and T. Liloglou, "p16 ${ }^{I N K 4}$ promoter hypermethylation is associated with invasiveness and prognosis of oral squamous cell carcinoma in an age dependent manner," Oral Oncology, vol. 47, no. 8, p. 776, 2011.

[56] M. T. Ruesga, A. Acha-Sagredo, M. J. Rodríguez et al., "p16 ${ }^{I N K 4 a}$ promoter hypermethylation in oral scrapings of oral squamous cell carcinoma risk patients," Cancer Letters, vol. 250, no. 1, pp. 140-145, 2007.

[57] O. Ozalp Yuregir, E. Yurtcu, E. Kizilkilic, N. E. Kocer, H. Ozdogu, and F. I. Sahin, "Detecting methylation patterns of p16, MGMT, DAPK and E-cadherin genes in multiple myeloma 
patients," International Journal of Laboratory Hematology, vol. 32, no. 2, pp. 142-149, 2010.

[58] P. A. Jones and P. W. Laird, "Cancer epigenetics comes of age," Nature Genetics, vol. 21, no. 2, pp. 163-167, 1999.

[59] P. Indovina, A. Acquaviva, G. De Falco et al., "Downregulation

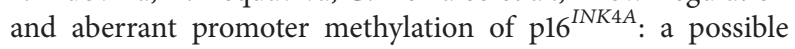
novel heritable susceptibility marker to retinoblastoma," Journal of Cellular Physiology, vol. 223, no. 1, pp. 143-150, 2010.

[60] A. G. Knudson Jr., "Mutation and cancer: statistical study of retinoblastoma," Proceedings of the National Academy of Sciences of the United States of America, vol. 68, no. 4, pp. 820-823, 1971.

[61] Y. Suga, K. Miyajima, T. Oikawa et al., "Quantitative p16 and ESR1 methylation in the peripheral blood of patients with nonsmall cell lung cancer," Oncology Reports, vol. 20, no. 5, pp. 11371142, 2008.

[62] M. Hasegawa, H. H. Nelson, E. Peters, E. Ringstrom, M. Posner, and K. T. Kelsey, "Patterns of gene promoter methylation in squamous cell cancer of the head and neck," Oncogene, vol. 21, no. 27, pp. 4231-4236, 2002.

[63] N. Shah, B. Lin, Z. Sibenaller et al., "Comprehensive analysis of MGMT promoter methylation: correlation with MGMT expression and clinical response in GBM," PLoS ONE, vol. 6, no. 1, Article ID e16146, 2011.

[64] J. Paluszczak, P. Misiak, M. Wierzbicka, A. Woźniak, and W. Baer-Dubowska, "Frequent hypermethylation of DAPK, RARbeta, MGMT, RASSF1A and FHIT in laryngeal squamous cell carcinomas and adjacent normal mucosa," Oral Oncology, vol. 47, no. 2, pp. 104-107, 2011.

[65] H. Mitomi, N. Fukui, N. Tanaka et al., "Aberrant p16 ${ }^{I N K 4 a}$ methylation is a frequent event in colorectal cancers: prognostic value and relation to mRNA expression and immunoreactivity," Journal of Cancer Research and Clinical Oncology, vol. 136, no. 2, pp. 323-331, 2010.

[66] M. Pérez-Sayáns, J. M. Suárez-Peñaranda, P. Gayoso-Diz, F. Barros-Angueira, J. M. Gándara-Rey, and A. García-García, "P16" INK4a $/ \mathrm{CDKN} 2$ expression and its relationship with oral squamous cell carcinoma is our current knowledge enough?" Cancer Letters, vol. 306, no. 2, pp. 134-141, 2011.

[67] N. Taghavi, F. Biramijamal, M. Sotoudeh et al., "P16 ${ }^{I N K 4 a}$ hypermethylation and $\mathrm{p} 53$, p16 and MDM2 protein expression in esophageal squamous cell carcinoma," BMC Cancer, vol. 10, article 138, 2010.

[68] H. Zhang and I. Rosdahl, "Deletion in p16INK4a and loss of p16 expression in human skin primary and metastatic melanoma cells," International Journal of Oncology, vol. 24, no. 2, pp. 331335, 2004.

[69] M. Takeshima, M. Saitoh, K. Kusano et al., "High frequency of hypermethylation of p14, p15 and p16 in oral pre-cancerous lesions associated with betel-quid chewing in Sri Lanka," Journal of Oral Pathology and Medicine, vol. 37, no. 8, pp. 475-479, 2008.

[70] L. M. R. B. Arantes, A. C. de Carvalho, M. E. Melendez, A. L. Carvalho, and E. M. Goloni-Bertollo, "Methylation as a biomarker for head and neck cancer," Oral Oncology, vol. 50, no. 6, pp. 587-592, 2014. 


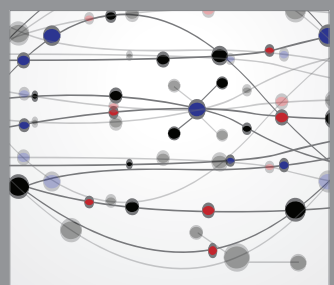

The Scientific World Journal
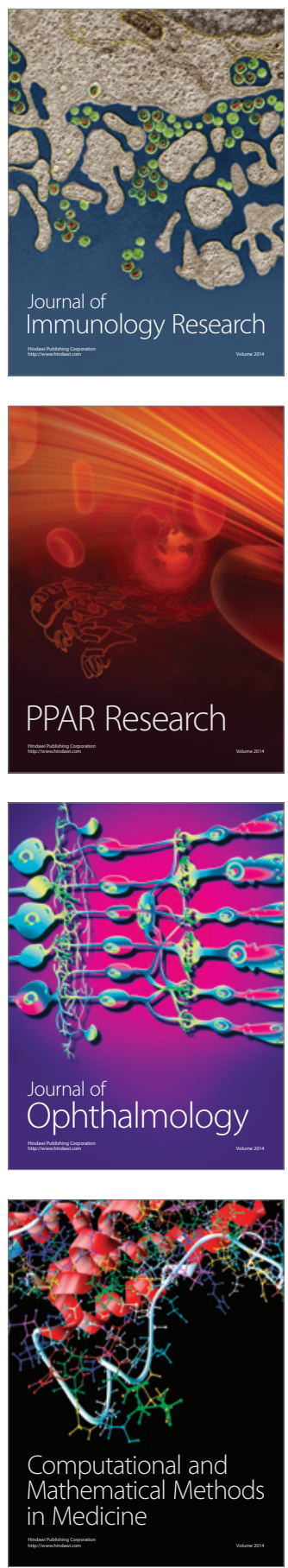

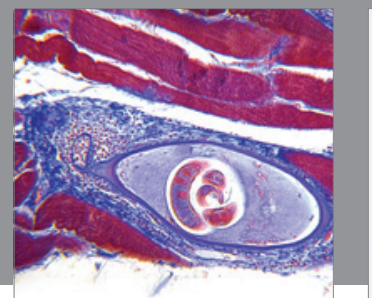

Gastroenterology

Research and Practice
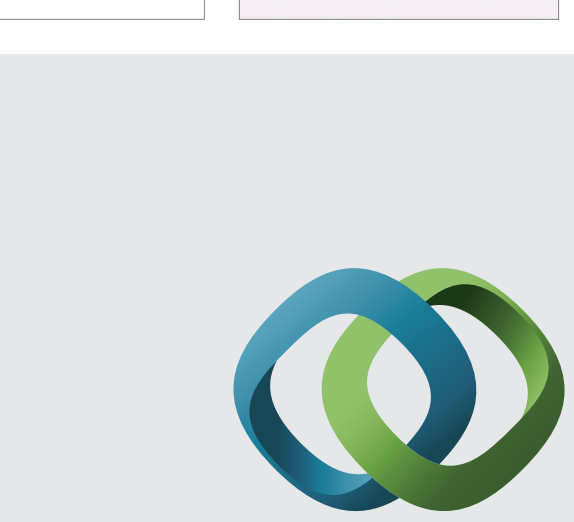

\section{Hindawi}

Submit your manuscripts at

http://www.hindawi.com
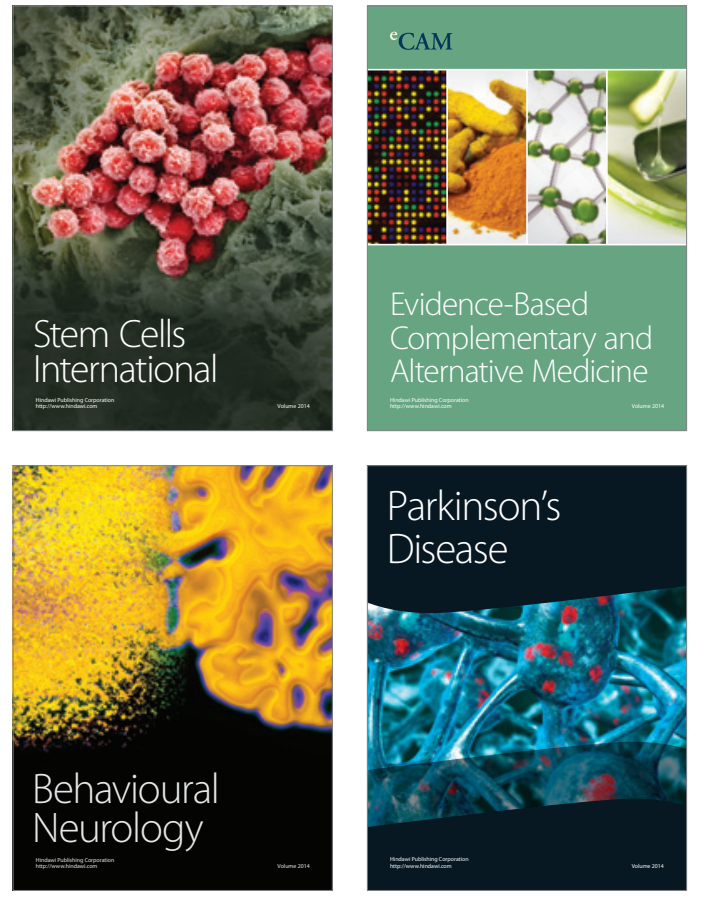
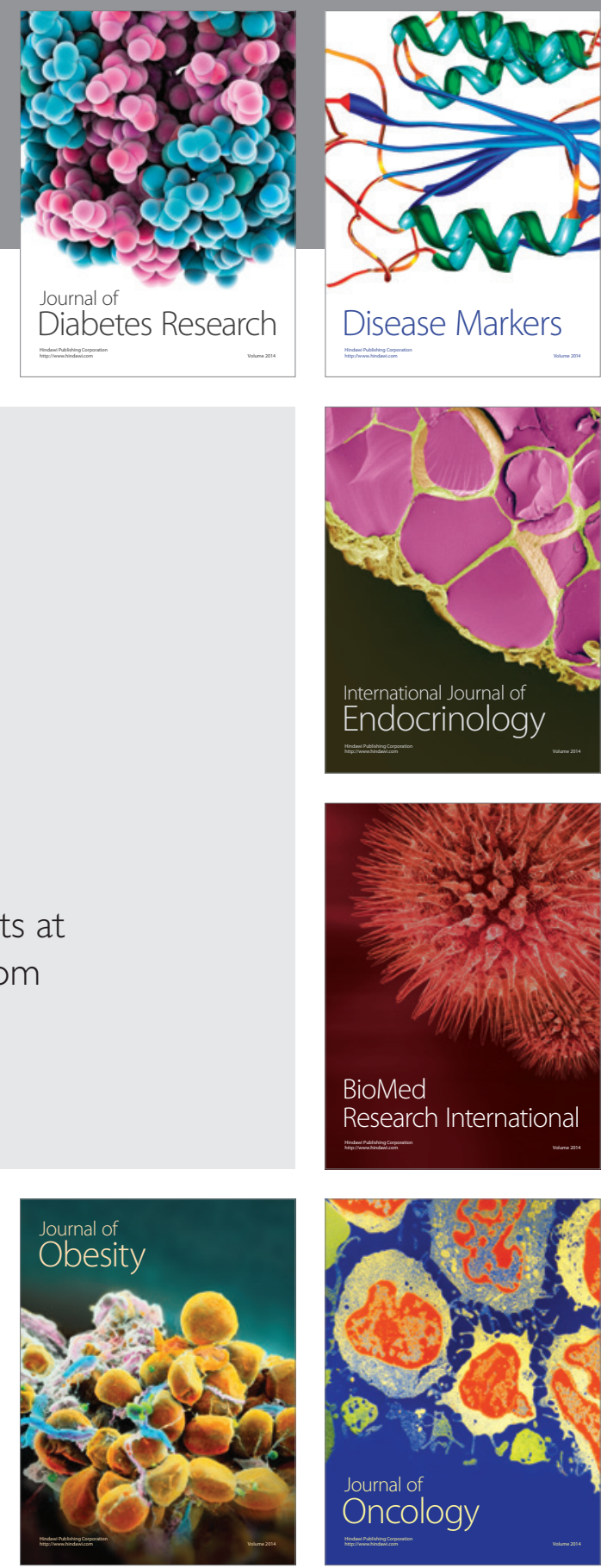

Disease Markers
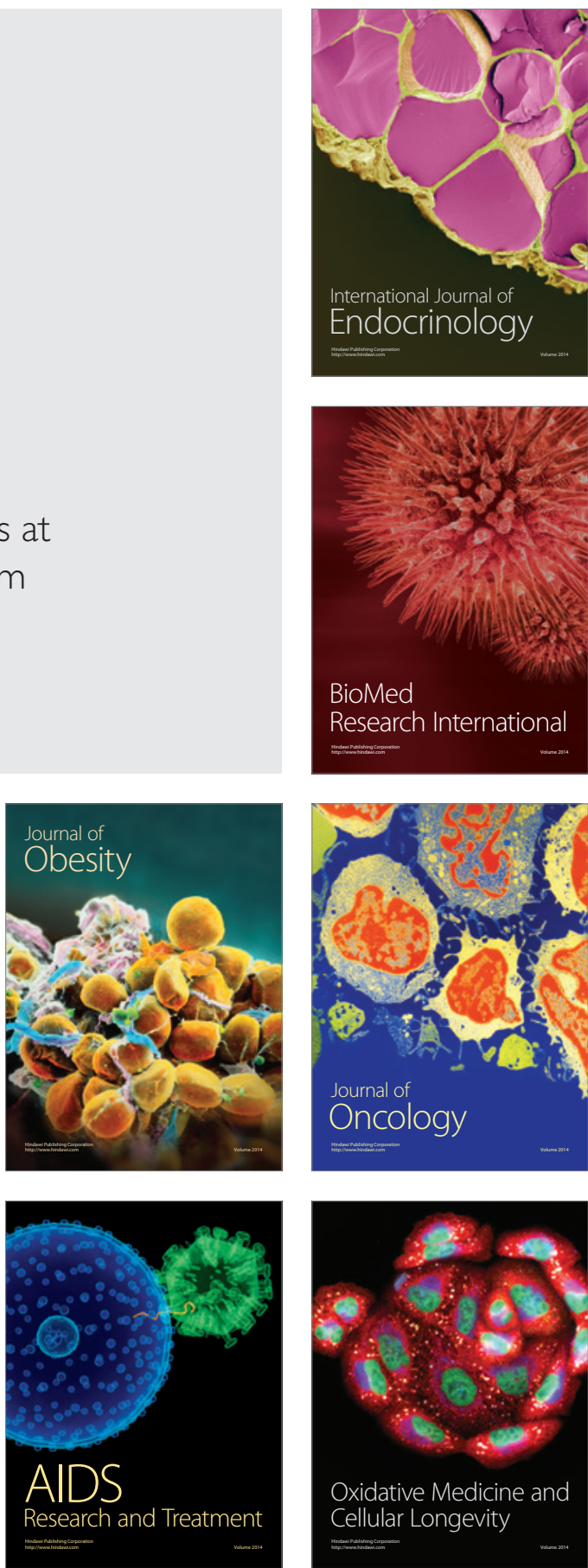